\title{
Amina Hallmann
}

\section{Gebundene Freiheit und strafrechtliche Schuld}

\section{Zur Reformbedürftigkeit des Schuldbegriffs vor dem Hintergrund}

neurowissenschaftlicher Erkenntnisse

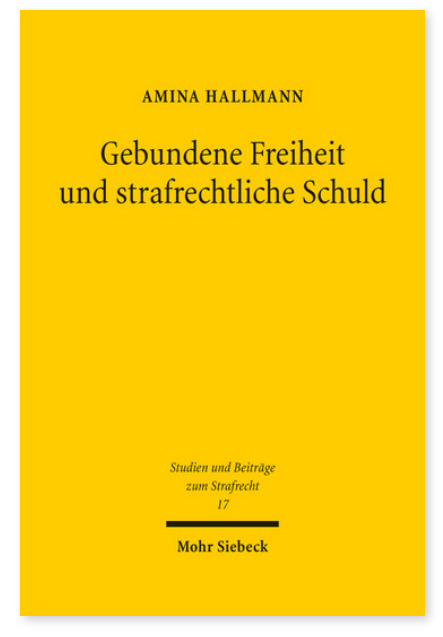

2017. XIV, 183 Seiten. StudStR 17

ISBN 978-3-16-155386-8

DOI 10.1628/978-3-16-155386-8

eBook PDF $69,00 €$

ISBN 978-3-16-155173-4

Leinen $69,00 €$
Gebundene Freiheit? Was auf den ersten Blick als Paradoxon erscheint, eröffnet sich als kompatibilistisches Freiheitskonzept, das insbesondere mit Blick auf die aktuelle Debatte um den Schuldbegriff entwickelt wurde. Häufig wird dabei unter Bezugnahme auf die neuronale Determiniertheit des Handelns eine Abkehr vom strafrechtlichen Schuldprinzip verlangt. Demgegenüber wird im Verlauf der vorliegenden Untersuchung mithilfe des Konzepts gebunden-freier Entscheidungen und einer eingehenden Analyse des Schuldprinzips, des Schuldbegriffs sowie des Kernbegriffs des »Anders-Handeln-Könnens« die zentrale Frage nach der tatsächlichen Möglichkeit freien und verantwortlichen Handelns einer wissenschaftlich fundierten Lösung zugeführt und so die Beibehaltung des Schuldprinzips ermöglicht. Darüber hinaus wird die Vereinbarkeit des Konzepts mit den Entschuldigungs- und Schuldausschließungsgründen sowie mit der Strafzumessungsschuld diskutiert.

Amina Hallmann Geboren 1988; Studium der Rechtswissenschaft an der Friedrich-Schiller-Universität Jena; 2016 Promotion; derzeit Referendarin am Landgericht Erfurt.
Jetzt bestellen:

https://mohrsiebeck.com/buch/gebundene-freiheit-und-strafrechtliche-schuld-9783161553868?no_cache=1

order@mohrsiebeck.com

Telefon: +49 (0)7071-923-17

Telefax: +49 (0)7071-51104 